\title{
Patients' Perception about the Influence of CRM Factors in Selected Health Care Units
}

\author{
Gangu Naidu Mandala*, Kavitha Desai, Jerlin Jose, Elizabeth Renju Koshy, Macherla Bhagyalakshmi \\ Department of Professional Studies, CHRIST Deemed to be University, Bengaluru, India
}

Received March 26, 2021; Revised June 8, 2021; Accepted July 19, 2021

\section{Cite This Paper in the following Citation Styles}

(a): [1] Gangu Naidu Mandala, Kavitha Desai, Jerlin Jose, Elizabeth Renju Koshy, Macherla Bhagyalakshmi , "Patients' Perception about the Influence of CRM Factors in Selected Health Care Units" Universal Journal of Public Health, Vol. 9, No. 6, pp. 410 - 417, 2021. DOI: 10.13189/ujph.2021.090608.

(b): Gangu Naidu Mandala, Kavitha Desai, Jerlin Jose, Elizabeth Renju Koshy, Macherla Bhagyalakshmi (2021). Patients' Perception about the Influence of CRM Factors in Selected Health Care Units. Universal Journal of Public Health, 9(6), 410 - 417. DOI: 10.13189/ujph.2021.090608.

Copyright $\bigcirc 2021$ by authors, all rights reserved. Authors agree that this article remains permanently open access under the terms of the Creative Commons Attribution License 4.0 International License

\begin{abstract}
The primary motivation behind this exploration study targets introducing a portion of the CRM ideas and components, CRM procedure to take proactive measures towards the customer to Health supplier to improve patients' satisfaction, loyalty fabricates a decent connection with patients and increment income. Patients' consideration, needs, and making associations with patients is an everyday schedule action in a well-being supplier. CRM is fundamental in this foundation customer satisfaction, the customer saw worth and customer relationship the board upgrade the relationship of the customer with the support up the general execution of the Hospital. The exploration configuration depends on quantitative examination, hence the information was gathered through an organized poll, five Likert-scales, SPSS, relapse, and SEM Model were utilized to figure out the results. This audits and distinguishes fundamental service quality, framework, the executives, and correspondence is identified with patients' satisfaction and loyalty in the private clinics in Andhra Pradesh. This investigation features the degree of service quality of the clinic services chosen by the test respondents.. This paper is an endeavour to discover connections between patients' views of customers' satisfaction and customers' loyalty and to propose ideas to have better CRM rehearses.
\end{abstract}

Keywords CRM, Healthcare, Patient's Loyalty, Patient's Perception, Service Quality

\section{Introduction}

Healthcare is a customer service industry. Organizations (and patient) live or bite the dust dependent on the quality of care given and the everyday connections among staff and patients. [1] The principal key to giving extraordinary customer service in the healthcare business is to quit regarding patients as customers whose sole reason for existing is to create income. Incredible customer service begins with taking a patient-driven viewpoint - seeing them as individuals your organization is intended to help.

Each worker in a healthcare organization is possibly a customer service agent - somebody whose every day exercises ought to be centred around improving the quality of care given to patients. [2] A few representatives will cooperate with patients straightforwardly while others work in supporting jobs (in the background), however everybody should move toward their work with a customer-service attitude.

Customers don't look for healthcare services when they are feeling great. They commonly draw in with healthcare organizations and individual suppliers to look for help for themselves (as the patient), a companion, or a relative. [3] Medical problems can be distressing. Patients are regularly stressed over their ailments just as monetary issues and this can strain associations with customer service staff.

While drawing in with healthcare organizations, patients hope for something else than treatment - they need to mind. [4] All the more significantly, patients need healthcare organizations and their workers to show they care about the person's requirements, circumstance, and prosperity, [5] 
which is shown during each cooperation.

Numerous healthcare encounters require more than one movement and regularly more than one arrangement. Experts may have to allude patients for tests, demand them to return for follow-up arrangements, or allude them to different professionals. The healthcare customer service experience isn't really obliged to a solitary arrangement or connection. Customer impressions depend on their comprehensive, start to finish insight.

Healthcare organizations can improve this piece of the customer service insight by upgrading how references and moves to different suppliers are performed. [6] Customer service frameworks can furnish specialists with the instruments to find reference assets, make arrangements for the customer, and submit orders for tests. This aide the patient feel the healthcare organization is worried about their general wellbeing and isn't simply regarding the person in question as a deal.

Indian healthcare conveyance framework is classified into two significant segments - public and private. The Government, for example public healthcare framework includes restricted optional and tertiary consideration foundations in key urban areas and spotlights on giving essential healthcare offices as essential healthcare places (PHCs) in Urban and provincial regions. [7] The private area gives most of optional, the expanding association of the private area in healthcare has fundamentally diminished the tension on the public authority's wellbeing framework and the private area has become a significant part in the Country's tertiary and quaternary consideration establishments with a significant focus in metros, level I, and level II urban communities.

The distributed report unmistakably expresses that medical care in the public area isn't just powerless yet in addition less valuable yet the private area is filling quick in the business. $76 \%$ of the absolute interest in the medical care industry comes from the private area and this deficient public interest in medical care framework has given huge freedoms to private clinics in the gigantic medical care market of India. Indian medical care area as of now gave work to 5 million individuals straightforwardly and in a roundabout way. It is in the field of deals, advertising, HR and IT, and so forth

In this country, medical care services additionally given by some beneficent trusts and social orders liberated from cost. [8] Dynamic ventures in the private business conveying quality clinical benefits have prevailing with regards to pulling in individuals from adjoining nations like the Middle East, Britain, and Europe, and so on.

Super-forte tertiary consideration emergency clinics commonly have every one of the clinical claims to fame under one rooftop and normally treat multi-organ disappointment, high danger, and injury cases. Super-forte medical clinics in the nation are the means for fortifying the medical services industry in the country. [9] Improvement of the current emergency clinic office, progressed gear, establishment, up-degree of innovation, advancement of abilities added to additional development increment pay, wellbeing mindfulness, [10] way of life illness and clinical protection and furthermore the explanations behind progress there means that Indian wellbeing industry will be a motor for the economy in future.

[11] The CRM assists with trading healthcare data to base consideration conveyance on the patient with associated wellbeing encourages improved consideration coordination, illness the executives, and the utilization of clinical practice rules to help lessen blunders and improve care.

\section{Review of Literature}

[5-10] The creators decide the significance that patients, medical caretakers, and attendant supervisors put on parts of care and measure medical attendants' consideration esteems dependent on their impression of their patients and medical attendant director care esteems and their craving to meet these consideration assumptions. Foundation: The writing has reported holes in how attendants and patients characterize quality and worth explicit consideration viewpoints, yet little is thought about the circumstance in the current constant quality improvement and patient-focused consideration climate, which stresses a customer center.

[8-11] Development and legitimacy testing of a poll intended to record patient satisfaction with essential medical care (PHC) services. Technique The examination was directed in 7 public clinics in Attica, with an example of 454 patients, clients of the services, chosen by defined arbitrary inspecting. A survey on patient satisfaction was planned dependent on the worldwide list of sources and following the progressive satisfaction model, comprising of 32 shut inquiries to be replied on a 5-point Likert scale. The members finished the survey and the resultant information were assessed utilizing corroborative and exploratory factor examination, and dependability investigation with Cronbach's alpha, and the Pearson connection coefficient.

[9-12] Chronic torment is notable to be affected by different social variables; notwithstanding, the effect of monetary issues on torment has not been broadly examined. Objective: The point of this examination was to explore the effect of the financial emergency on agony and quality of life in Greek patients experiencing constant torment. Study Design: The investigation utilized a planned, open-mark plan. Setting: The examination setting was the Pain Unit of Attikon University Hospital in Athens, Greece. Strategies: The investigation overviewed 200 haphazardly chose outpatients with persistent agony during two distinctive time spans (2012 and 2016). Patients finished an organized survey to evaluate the effect of the monetary emergency on numerous parts of torment and torment the board, medical services, and quality of life. Character qualities and stress 
were additionally assessed utilizing the DASS-42 and the LOT-R surveys.

[7-13] Patient security is a worldwide concern and is the main areas of medical care quality. Clinical blunder is a significant patient security concern, causing expansion in medical care cost because of mortality, bleakness, or delayed medical clinic stay. Point: The point of the investigation was to evaluate the discernments on patient wellbeing society among medical services suppliers (HCPs) at a public area tertiary consideration clinic in South India. Settings and Design: A clinic based cross-sectional investigation was led 1 year after patient security activities were carried out.

\section{Need for the Study}

The survey research studies and the writing on the service quality Healthcare Sector in India, especially in Andhra Pradesh state and the connected viewpoints uncovers that the degree of research on CRM in medical care areas is lacking. Despite the fact that numerous endeavours have been attempted on Health care public and private areas services prior, no complete work has been embraced covering the CRM rehearses in private areas in Andhra Pradesh. Subsequently, the proposed study means to examine the customer relationship the executives rehearse in medical services areas in Andhra Pradesh state.

\section{Objectives of the Study}

1. To identify and analyse the factors influencing the CRM and study the user's perception about the factors influencing CRM in selected health care units in Andhra Pradesh.

2. To critical analyse and evaluate customer relationship practices in health care unit.

3. To give suitable recommendations for development of CRM in the health care sectors.

\section{Scope of the Study}

The current examination, indeed, is an exploratory examination of the continuous CRM endeavours of the medical care area in Andhra Pradesh. Its geological region reaches out to the limits of Andhra Pradesh state. The survey research studies and the writing on the service quality Healthcare Sector in India, especially in Andhra Pradesh state and the connected viewpoints uncovers that the degree of research did on CRM in medical care areas is lacking. Despite the fact that numerous endeavours have been attempted on Health care public and private areas services prior, no complete work has been embraced covering the CRM rehearses in private areas in Andhra Pradesh. Subsequently, the proposed study means to examine the customer relationship the executives rehearses in medical services areas in Andhra Pradesh state.

\section{Hypothesis}

H1: CRM has a significant impact on patient Loyalty.

H2: CRM has a significant influence on patient Satisfaction.

H3: Customer Loyalty has a significant and positive impact on patient Satisfaction.

\section{Research Methodology}

\section{Methods of Data Collection}

To reach above expressed targets the essential information is gathered through an organized poll, five Likert-scales strategy and connection with the respondents. Auxiliary information is gathered through distributed sources like Journals, Books and e-sources.

\section{Period of the Study}

The information identified with present work has been gathered Primary information from the sources accessible and the time of study covers four years 2020 to 2021.

\section{Statistical Tools and Techniques}

The current examination utilized diverse measurable instruments and strategies for the investigation and understanding of information, for example, factor investigation and various relapse investigations utilizing SPSS.

\section{Sample Size}

The test chose for the examination is proposed to covers various chose private emergency clinic units in Andhra Pradesh. Absolutely 1256 respondents are chosen on the basis arbitrarily. Out of inspecting, just 912 surveys are filled by patients and staying 100 filled by clinics Doctors and Management. 


\begin{tabular}{|c|c|c|c|c|}
\hline Division & Tire Cities & List of selected Healthcare units (Multispecialty) & $\begin{array}{l}\text { No of Patient } \\
\text { in interviewed }\end{array}$ & $\begin{array}{l}\text { Doctors'/ } \\
\text { Management } \\
\text { Sample size }\end{array}$ \\
\hline \multirow{9}{*}{ Visakhapatnam } & \multirow{5}{*}{ Visakhapatnam } & A N Beach Hospital & 36 & \multirow{9}{*}{31} \\
\hline & & Apollo Hospitals Enterprise Ltd Vsp & 40 & \\
\hline & & Apoorva Hospital Apoorva Health Services Pvt Ltd & 30 & \\
\hline & & $\begin{array}{l}\text { Durga Hospitals A Unit Of Smilecare Multispeciality } \\
\text { Hospitals Pvt Ltd }\end{array}$ & 30 & \\
\hline & & $\begin{array}{l}\text { Dr Mangamma Hospital A Unit Of Sri Sai Dhanwanthari } \\
\text { Health Care Pvt Ltd }\end{array}$ & 24 & \\
\hline & \multirow{2}{*}{ Gajuwaka } & Gajuwaka Hospitals Pvt Ltd R K Hospitals & 24 & \\
\hline & & Indus Hospital & 30 & \\
\hline & \multirow{2}{*}{ Narisipatnam } & Krishna Maternity And Nursing Home & 30 & \\
\hline & & Manipal Woman And Child Hospital & 32 & \\
\hline \multirow{9}{*}{ Vizianagaram } & \multirow{5}{*}{ Vizianagaram } & A J Global Health Care Hospital & 28 & \multirow{9}{*}{24} \\
\hline & & Indira Nursing Home & 32 & \\
\hline & & Muvva Gopala Hospitals Pvt Ltd & 34 & \\
\hline & & Tirumala Multi Speciality Hospitals India Pvt Ltd & 24 & \\
\hline & & Venkatarama Hospital & 20 & \\
\hline & \multirow{4}{*}{$\begin{array}{l}\text { Bobbili } \\
\text { Parvathipuram }\end{array}$} & Choudary Hospital And Diagnostics & 36 & \\
\hline & & Jayasree Hospital & 34 & \\
\hline & & Vandana Hospital & 32 & \\
\hline & & Sri Venkateswara Hospital & 36 & \\
\hline \multirow{6}{*}{ Srikakulam } & \multirow{3}{*}{ Srikakulam } & Baggu Sarojini Devi Hospital & 34 & \multirow{6}{*}{25} \\
\hline & & Kamala Hospital & 36 & \\
\hline & & Suraksha Kidney And Maternity Centre & 34 & \\
\hline & \multirow{3}{*}{ Palasa } & Kims Sai Seshadri Hospital & 30 & \\
\hline & & Vaatsalya Hospital Narasannapet & 28 & \\
\hline & & Dr Golivi Hospitals Pvt Ltd & 30 & \\
\hline \multirow{6}{*}{ East Godavari } & \multirow{4}{*}{ Kakinada } & $\begin{array}{l}\text { Apollo Hospitals Kakinada (Samudra Health Care } \\
\text { Enterprises Ltd.), Kakinada }\end{array}$ & 32 & \multirow{6}{*}{20} \\
\hline & & Surya Global Hospital, Kakinada & 28 & \\
\hline & & Hope International Hospital, Kakinada & 24 & \\
\hline & & Sri Gowthami Multi Speciality Hospital & 30 & \\
\hline & \multirow{2}{*}{ Rajahmundry } & Raju Neuro And Multi Specialty Hospital & 34 & \\
\hline & & Rajahmundry Hospitals & 30 & \\
\hline \multicolumn{3}{|l|}{ Total } & 912 & 100 \\
\hline
\end{tabular}


(Measurement model for constructs under CRM - patients' perceptive)

\begin{tabular}{|c|c|c|c|c|c|}
\hline Latent Variable & Items & Standardized Loadings & $\begin{array}{l}\text { Composite } \\
\text { Reliability* }\end{array}$ & $\begin{array}{c}\text { Cronbach } \\
\text { Alpha }\end{array}$ & $\begin{array}{c}\text { Average Variance Extracted } \\
\text { (AVE) }\end{array}$ \\
\hline \multirow{9}{*}{ Quality Services (QS) } & Q.S_1 & 0.303 & \multirow{9}{*}{0.650} & \multirow{9}{*}{0.653} & \multirow{9}{*}{0.179} \\
\hline & Q.S_2 & 0.422 & & & \\
\hline & Q.S_3 & 0.488 & & & \\
\hline & Q.S_4 & 0.476 & & & \\
\hline & Q.S_5 & 0.385 & & & \\
\hline & Q.S_6 & 0.418 & & & \\
\hline & Q.S_7 & 0.415 & & & \\
\hline & Q.S_8 & 0.378 & & & \\
\hline & Q.S_9 & 0.411 & & & \\
\hline \multirow{7}{*}{ Infrastructure (INFRA) } & INF_1 & 0.488 & \multirow{7}{*}{0.685} & \multirow{7}{*}{0.697} & \multirow{7}{*}{0.236} \\
\hline & INF_2 & 0.488 & & & \\
\hline & INF_3 & 0.502 & & & \\
\hline & INF_4 & 0.506 & & & \\
\hline & INF_5 & 0.474 & & & \\
\hline & INF_6 & 0.518 & & & \\
\hline & INF_7 & 0.439 & & & \\
\hline \multirow{7}{*}{$\begin{array}{l}\text { Management } \\
\text { (MANAG) }\end{array}$} & MAN_1 & 0.326 & \multirow{7}{*}{0.610} & \multirow{7}{*}{0.660} & \multirow{7}{*}{0.216} \\
\hline & MAN_2 & 0.515 & & & \\
\hline & MAN_3 & 0.418 & & & \\
\hline & MAN_4 & 0.512 & & & \\
\hline & MAN_5 & 0.447 & & & \\
\hline & MAN_6 & 0.485 & & & \\
\hline & MAN_7 & 0.510 & & & \\
\hline \multirow{4}{*}{$\begin{array}{l}\text { Communication } \\
\text { (COMM) }\end{array}$} & COM_1 & 0.475 & \multirow{4}{*}{0.609} & \multirow{4}{*}{0.611} & \multirow{4}{*}{0.205} \\
\hline & COM_2 & 0.520 & & & \\
\hline & COM_3 & 0.457 & & & \\
\hline & COM_4 & 0.435 & & & \\
\hline \multirow{5}{*}{ Customer Loyalty } & LOY_1 & 0.447 & \multirow{5}{*}{0.574} & \multirow{5}{*}{0.581} & \multirow{5}{*}{0.216} \\
\hline & LOY_2 & 0.517 & & & \\
\hline & LOY_3 & 0.410 & & & \\
\hline & LOY_4 & 0.540 & & & \\
\hline & LOY_5 & 0.328 & & & \\
\hline \multirow{4}{*}{ Customer Satisfaction } & SAT_1 & 0.487 & \multirow{4}{*}{0.556} & \multirow{4}{*}{0.569} & \multirow{4}{*}{0.237} \\
\hline & SAT_2 & 0.419 & & & \\
\hline & SAT_3 & 0.527 & & & \\
\hline & SAT_4 & 0.518 & & & \\
\hline
\end{tabular}

Convergent validity is shown when every estimation thing associates unequivocally with its accepted hypothetical build. As such, the things that are the markers of a development ought to combine or share a high extent of change in like manner. The worth reaches somewhere in the range of nothing and one $(0-1)$. The ideal degree of normalized loadings for intelligent pointers is 0.70 however 0.60 is viewed as an adequate level (Barclay et al.,
1995). As needs are, from Table 2, it is seen that the majority of the things under each build have loadings more prominent than 0.60 . Subsequently, it tends to be closed the event of joined legitimacy yet less short to finish union. Talking about the Reliability factor, it is seen from Table 1 that Quality Services has a composite dependability estimation of 0.650; Infrastructure with a composite unwavering quality of 0.685 , Management with 0.610 and 
Communication with 0.609 , the patient Loyalty has a composite dependability estimation of 0.574 and patient Satisfaction with 0.556 .

The discoveries uncover that the vast majority of the developments are higher than the necessary unwavering quality. Subsequently, we infer that every one of the things assembled totally combine to its separate measurements. Moreover, the Cronbach alpha qualities across every one of the measurements portrayed in the above table have more than 0.60 which is again higher than the necessary limit esteem. Consequently, we can again reason that there is a consistency in the information and furthermore the poll has been managed to the important respondents with applicable inquiries.

\section{Hypothesis Results and Discussion}

Customer Relationship Management affecting patient Loyalty and Satisfaction - Patients' Perception was examined through the utilization of Structural Equation Modelling (SEM) (Figure:01). A Confirmatory Factor Analysis (CFA) went before the SEM to check the dependability and legitimacy of patient satisfaction and patient Loyalty-Patients' insightful.

- SEM result for the impact of customer relationship on the board on patient loyalty and satisfaction. From the outcome, it is plainly seen that Chi-square/df ( $\chi 2 / \mathrm{df})$ is 1.700 (which is less 3) and Goodness of Fit record (GFI) got is 0.880 as against the suggested estimation of above 0.90; The Adjusted Goodness of Fit Index (AGFI) is 0.866 as against the suggested estimation of above 0.90 also. The Normed Fit Index (NFI), Relative Fit file (RFI), Comparative Fit file (CFI) are 0.806, 0.876, 0.840 individually as against the suggested level of above 0.90 . RMSEA is 0.040 and is well underneath the suggested furthest reaches of 0.10 . Subsequently, the model shows a by and large satisfactory fit and is an over recognized model. Moreover, we finish up the above SEM Model (Figure 1) is a solid match.

- The perception concerning the relapse results is the impact of customer relationship on the board on patient loyalty and satisfaction. In like manner, it is seen that the p-estimation of the connection among CRM and patient Loyalty $(~(=0.805, C \cdot R=5.881$, $\mathrm{p}<0.05$ ) is not exactly the importance alpha degree of 0.05 , we acknowledge H1.

- It can be reasoned that CRM has a huge impact/sway on patient Loyalty.

It is seen that the p-estimation of the connection among CRM and patient Satisfaction $(ß=0.651$, C.R $=$ 4.161, $\mathrm{p}<0.05$ ) is not exactly the importance alpha degree of 0.05 , we acknowledge $\mathrm{H} 2$.

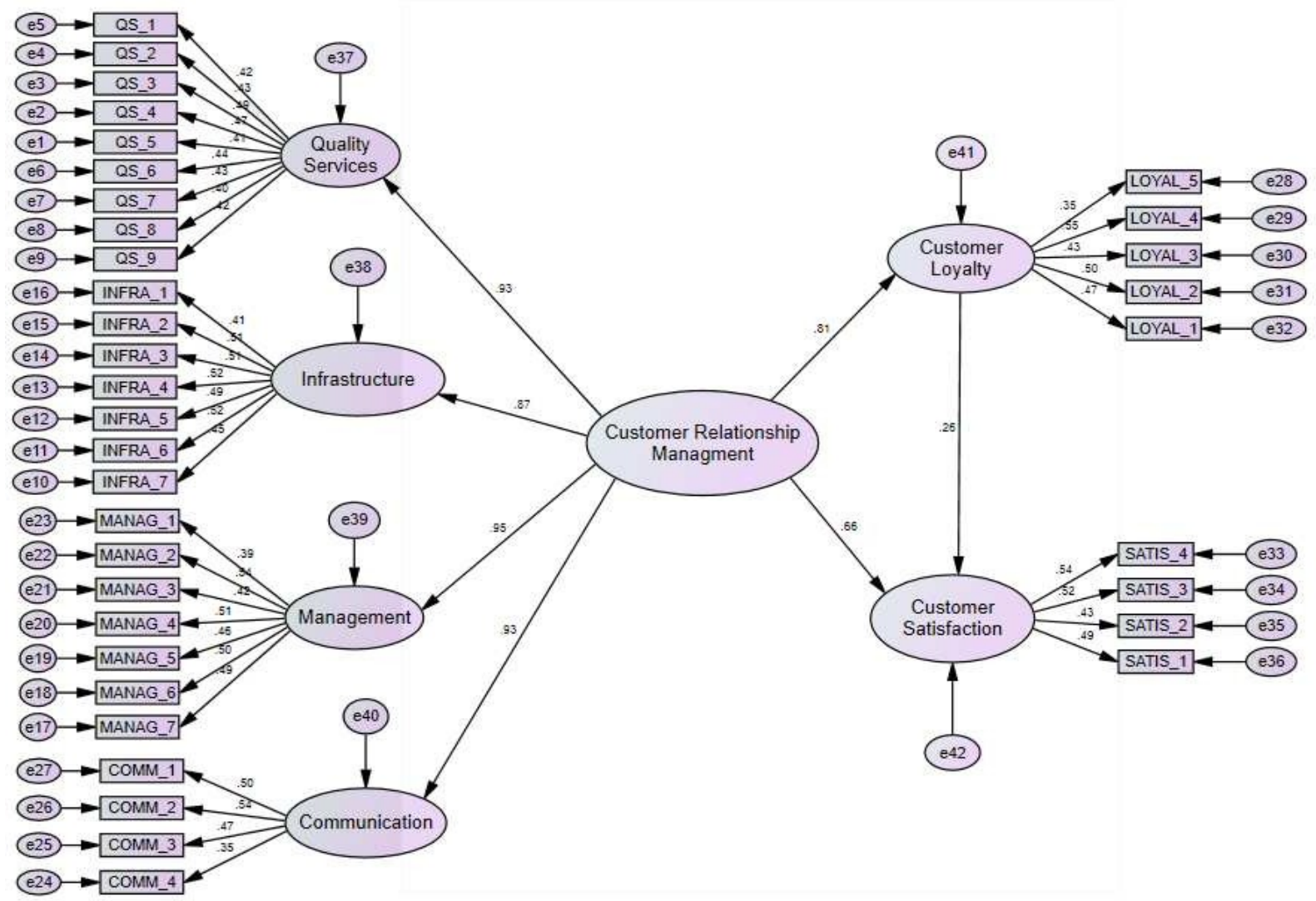

Figure 1. SEM model for CRM influencing patient's loyalty and satisfaction - patients' perception 
- It can be inferred that CRM has a critical impact/sway on patient Satisfaction.

- Finally, it is seen that the p-estimation of the connection between patient Loyalty and patient

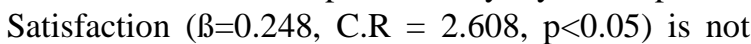
exactly the importance alpha degree of 0.05 , we acknowledge $\mathrm{H} 3$.

- Conclude that there is measurable proof to presume that patient Loyalty has a critical (genuinely) and positive impact or effect on patient Satisfaction.

Customer Relationship Management affecting patient Satisfaction - Doctors' Perception was broken down through the use of SEM, a CFA went before the SEM to check the unwavering quality and legitimacy of patient satisfaction and patient Loyalty-Doctors' discerning.

- CRM and satisfaction. From the outcome, it is unmistakably seen that Chi-square/df $(\chi 2 / \mathrm{df})$ is 2.856 (which are less 3 ) and Goodness of Fit record (GFI) acquired is 0.852 as against the suggested estimation of above 0.90; The Adjusted Goodness of Fit Index (AGFI) is 0.801 as against the suggested estimation of above 0.90 too. The Normed Fit Index (NFI), Relative Fit record (RFI), Comparative Fit list (CFI) are 0.832, $0.876,0.886$ separately as against the suggested level of above 0.90. RMSEA is 0.080 and is well underneath the suggested furthest reaches of 0.10 . Thus, we close the above SEM Model is a solid match.

- The perception as for the relapse results are impacted on p-estimation of the connection among CRM and patient Satisfaction $(\Omega=0.873$, C. $R=5.630, p<0.05)$ is not exactly the importance alpha degree of 0.05 , we acknowledge $\mathrm{H} 1$.

- It can be reasoned that CRM impacts patient Satisfaction.

\section{Suggestions}

- Effective services in emergency clinics today don't mean giving just progressed clinical innovation, yet additionally updating support services for speedier information recording, assemblage, and investigation. Those emergency clinics that are in fact lingering behind ought to step by step begin executing trend-setting innovations in treatment and furthermore in patient support services.

- The patients and representatives should be urged by healthcare suppliers to submit questions when they deal with any issues on the clinic grounds. For that, a grievances or ideas box should be given and a move should be made by the medical clinic specialists against such protests to improve the service.

- Regular Training programs/workshops for the medical clinic staff unquestionably will improve the quality of existing CRM rehearses
The emergency clinic the board needs to talk about with staff individuals for improving the patient's satisfaction, giving their great treatment and correspondence to improve the CRM and get patients satisfaction to construct a decent relationship.

\section{Limitations of the Study}

1. The investigation covers just the chose medical care units in Andhra Pradesh.

2. This study is restricted to patient-focused consideration with an accentuation on the administrative viewpoints.

3. CRM in the medical services area has various discrete practices. Along these lines, it is hard to incorporate all the CRM rehearses in a solitary report.

\section{Conclusions}

Customer relationship with the board (CRM) is significant for emergency clinic services as it has been for some other organizations. A clinic helps in re-establishing and keeping up the soundness of individuals. Well-being suppliers zeroed in on patient satisfaction, the patient saw worth and CRM is key drivers to construct patient loyalty. Well-being suppliers improve the trust and responsibility levels of patient towards the service; Hospital the board ought to be fuse CRM rehearses it assists with overhauling the quality of service. The wellbeing supplier ought to present preparing areas for their staff individuals that will improve their degrees of patient loyalty which at last prompts more patients. A CRM framework is an inventive innovation that makes the way toward obtaining, creating, and keeping up associations with patients more successful and efficient. The benefits of CRM could be improved patient service, a decrease in cost, and better maintenance of patients.

\section{REFERENCES}

[1] Wadson, K, Nurses need training and policies to address barriers to use of mobile devices and apps for direct patient care in hospital settings, Evidence Based Library and Information PracticeOpen Access, Volume 13, Issue 1, 2018, Pages 39-42.

[2] Bracco, M.M., Mafra, A.C.C.N., Abdo, A.H., Colugnati, F.A.B., Dalla, M.D.B., Demarzo, M.M.P., Abrahamsohn, I., Rodrigues, A.P., De Almeida Delgado, A.V.F., Dos Prazeres, G.A., Teixeira, J.C., Jr., Possa, S., Implementation of integration strategies between primary care units and a regional general hospital in Brazil to update and connect health care professionals: A quasi-experimental study protocol, BMC Health Services ResearchOpen Access, Volume 16, Issue 1, 12 August 2016, Article number 380, 
[3] Fitzgerald, G., Toloo, G.S., Aitken, P., Keijzers, G., Scuffham, P, Public use and perceptions of emergency departments: A population survey, EMA - Emergency Medicine Australasia, Volume 27, Issue 4, 1 August 2015, Pages 336-342.

[4] Gagnon, M.-P., Desmartis, M., Poder, T., Witteman, W, Effects and repercussions of local/hospital-based health technology assessment (HTA): A systematic review, Systematic ReviewsOpen Access, Volume 3, Issue 1, May 01, 2015, Article number 129

[5] Young, W.B., Minnick, A.F., Marcantonio, R, how wide is the gap in defining quality care? Comparison of patient and nurse perceptions of important aspects of patient care, Journal of Nursing Administration, Volume 26, Issue 5, May 1996, Pages 15-20.

[6] Liu, W., Walsh, T., The impact of implementation of a clinically integrated problem-based neonatal electronic health record on documentation metrics, provider satisfaction, and hospital reimbursement: A quality improvement project, Journal of Medical Internet Research, Volume 20, Issue 6, June 2018, Article number e40,

[7] Rajalatchumi, A., Ravikumar, T.S., Muruganandham, K., Thulasingam, M., Selvaraj, K., Reddy, M.M., Jayaraman, B, Perception of patient safety culture among health-care providers in a Tertiary Care Hospital, South India, Journal of Natural Science, Biology and MedicineOpen Access,
Volume 9, Issue 1, January-June 2018, Pages 14-18.

[8] Goula, A., Latsou, D., Natsis, C., Sarris, M., Soulis, S., Pierrakos, G., Development and validation of a patient satisfaction questionnaire for use in primary health care, Archives of Hellenic MedicineOpen Access, Volume 36, Issue 1, 1 January 2019, Pages 88-95.

[9] Batistaki, C., Mavrocordatos, P., Smyrnioti, M.-, Lyrakos, G., Kitsou, M.-C., Stamatiou, G., Kostopanagiotou, G., Patients' perceptions of chronic pain during the economic crisis: Lessons learned from Greece, Pain PhysicianOpen Access, Volume 21, Issue 5, September-October 2018, Pages E533-E543.

[10] Emmanuel Kobina Mesi Edzie, Klenam Dzefi-Tettey, Philip Narteh Gorleku, Adu Tutu Amankwa, Ewurama Andam Idun, Edmund Kwakye Brakohiapa, Eric Aidoo, Julius John Essoun, Frank Quarshie, Henry Kusodzi, Abdul Raman Asemah, "Perception of Non-radiation Healthcare Workers about Radiation in Cape Coast Metropolis, Ghana," Universal Journal of Public Health, Vol. 9, No. 2, pp. 57 - 66, 2021. DOI: 10.13189/ujph.2021.090204.

[11] Elizabeth Kateta, Josephine De Villiers, Hermine Iita, "Knowledge, Attitudes and Practices of Patients Diagnosed with Tuberculosis Related to Tuberculosis Treatment Adherence in Keetmanshoop District, Namibia," Universal Journal of Public Health, Vol. 8, No. 2, pp. 43 - 56, 2020. DOI: 10.13189/ujph.2020.080201. 